\title{
Correction to: Evaluating changes in electronic gambling machine policy on user losses in an Australian jurisdiction
}

Matthew Stevens ${ }^{1 *}$ and Charles Livingstone ${ }^{2}$

\section{Correction to: BMC Public Health (2019) 19:517 \\ http://orcid.org/10.1186/s12889-019-6814-1}

It was highlighted that in the original article [1] Fig. 3 and Fig. 4 legends were incorrect. This Correction article shows Fig. 3 and Fig. 4 with their correct legend.

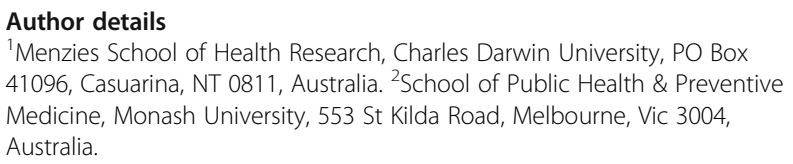

Received: 11 July 2019 Accepted: 11 July 2019

Published online: 23 July 2019

\section{Reference}

1. Stevens, Livingstone. Evaluating changes in electronic gambling machine policy on user losses in an Australian jurisdiction. BMC Public Health. 2019; 19:517. https://doi.org/10.1186/s12889-019-6814-1.

\footnotetext{
* Correspondence: matthew.stevens@menzies.edu.au

${ }^{1}$ Menzies School of Health Research, Charles Darwin University, PO Box

41096, Casuarina, NT 0811, Australia

Full list of author information is available at the end of the article
} 


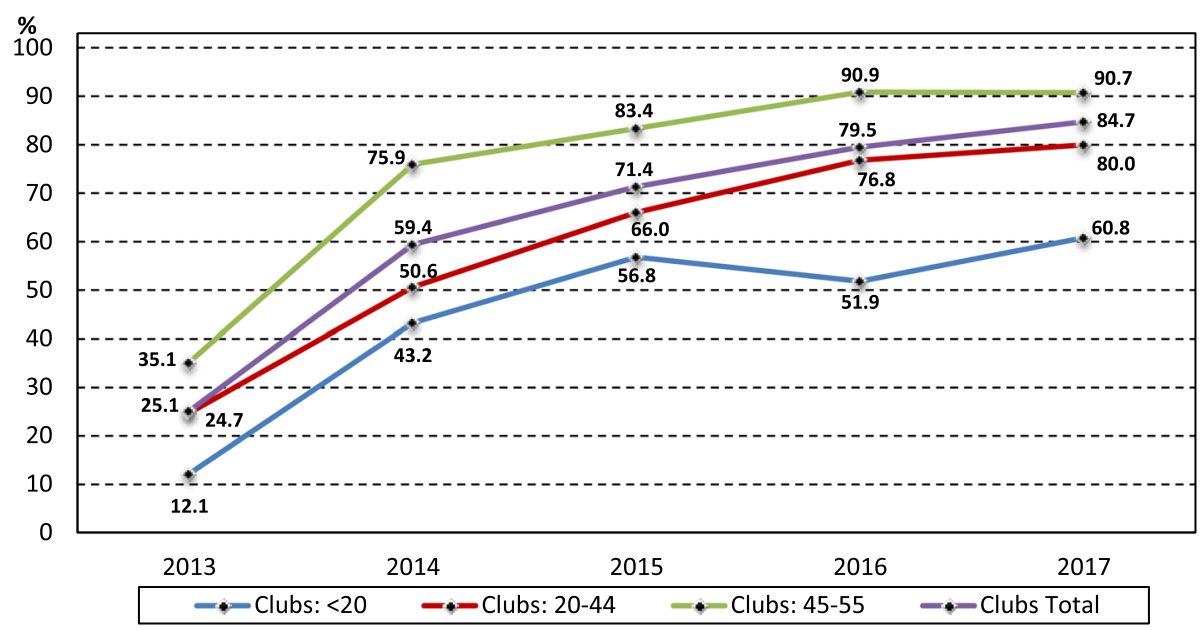

Fig. 3 Percentage of EGMs with note acceptors in NT clubs by club size, 2013 to 2017

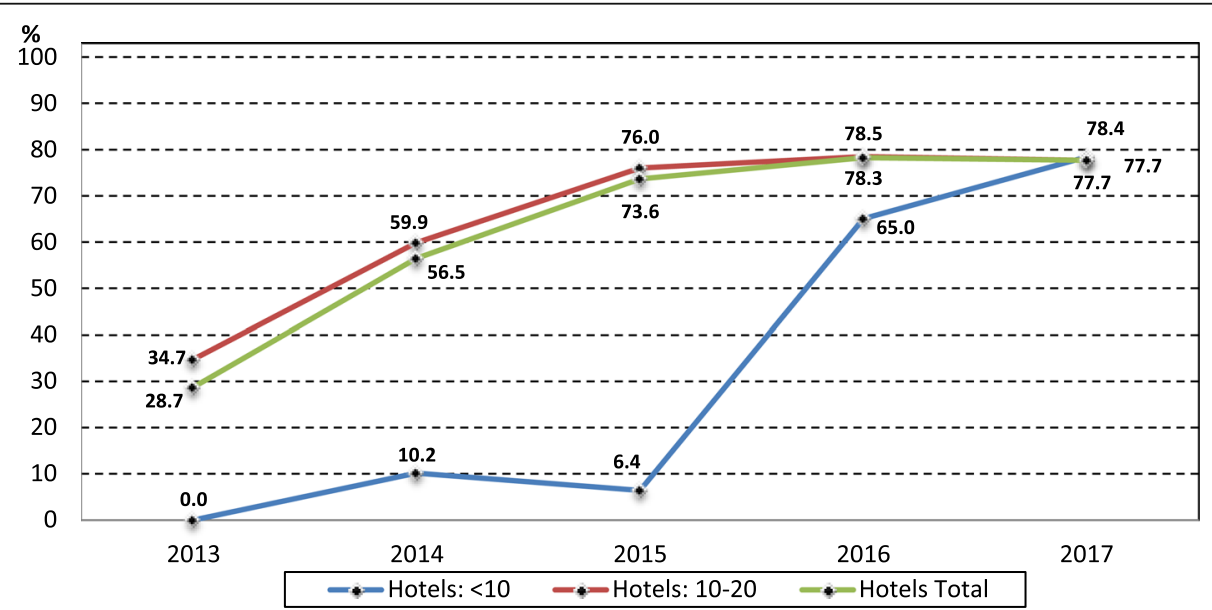

Fig. 4 Percentage of EGMs with note acceptors in NT hotels by hotel size, 2013 to 2017 